\title{
Antiinflammatory Activity of Slime Extract from Giant African Snail (Lissachatina fulica)
}

\author{
C. WIYA, N. NANTARAT AND K. SAENPHET ${ }^{1 *}$ \\ Department of Biology, Faculty of Science, ${ }^{1}$ Research Center in Bioresources for Agriculture, Industry and Medicine, Chiang \\ Mai University, Chiang Mai 50200, Thailand
}

Wiya et al.: Antiinflammatory Activity of Snail Slime

\begin{abstract}
The present study aims to investigate the antiinflammatory activity of the slime extracts from the giant African snail, Lissachatina fulica. In this study, aqueous and ethanol extracts of the snail slime were evaluated for antiinflammatory activities in vitro. The aqueous extract showed greater antiinflammatory activities than the ethanol extract. The aqueous extract was further tested for antiinflammatory activity in vivo. For acute inflammation, the ear oedema assay was used to screen the slime extract. The results revealed that application of $2 \mathrm{mg} / \mathrm{ear}$ extract or phenylbutzone could significantly reduce oedema when compared with ethanol-treated ears. For chronic inflammatory test, the cotton pellet granuloma model was employed to determine the activity of the slime extract. It was found that 2.5 and $6.25 \%$ extract could significantly reduce transudative and granuloma weights. Moreover, the extracts also reduced malondialdehyde and increased superoxide dismutase in the granuloma tissue of the induced rats. In conclusion, the slime extract showed antiinflammatory activity both in vitro and in vivo. The antiinflammatory activity was also observed against acute and chronic inflammations, which suggested that the slime extracts has the potential to be developed into antiinflammatory products.
\end{abstract}

Key words: Antiinflammatory activity, giant African snail, Lissachatina fulica, slime extract

Inflammation is a common response to detrimental stimuli such as irritants, pathogens or damaged cells. The outcomes of inflammatory reaction are stimuli elimination and tissue repair ${ }^{[1]}$. Although inflammation is a beneficial strategy, the progression of the inflammatory process often causes unwanted outcomes such as pain, swelling, redness and loss of function of inflamed cells or even oxidative stress. Non-steroidal antiinflammatory drugs (NSAIDs) were developed to relieve these inflammatory symptoms, especially pain. Unfortunately, treatment of inflammation with NSAIDs produces negative side effects, for instance stomach irritation and cardiovascular problems ${ }^{[2,3]}$. Recently, natural products that have antiinflammatory properties have become an alternative way to relieve these symptoms. There are several scientific reports about antiinflammatory properties of natural products, mainly from medicinal plants, but there are not many about animal product.

Snail slime is a secretory fluid produced from mucus glands located in the skin including the foot plate. It is mainly used to reduce friction and protect its foot during

*Address for correspondence

E-mail: stit.lilo123@gmail.com

May-June 2020 locomotion. Moreover, carnivorous slug or shell-less snail secrete slime to maintain moisture and to help their mating and hunting activities ${ }^{[4]}$. Snail slime has become a remarkable ingredient in cosmetic products because it contains some biochemical substances, which have properties useful to skin care, such as alantoin, elastin, collagen and hyaluronic acid ${ }^{[5]}$. Furthermore, the slime has also been reported to have pharmacological activities including antibacterial activity ${ }^{[6,7]}$, antioxidant and regenerative properties ${ }^{[8]}$ and anticancer property ${ }^{[9]}$. Interestingly, the slime extracted from Achatina fulica has been reported to heal incised wounds faster than self-healing can ${ }^{[10]}$. In the wound healing process, the healing stages start after inflammatory products and dead cells were cleared out of the wound site ${ }^{[10,11]}$. Therefore, inflammation is an important stage, which This is an open access article distributed under the terms of the Creative
Commons Attribution-NonCommercial-ShareAlike 3.0 License, which
allows others to remix, tweak, and build upon the work non-commercially,
as long as the author is credited and the new creations are licensed under
the identical terms

Accepted 20 May 2020 Revised 23 April 2020 Received 21 July 2019 Indian J Pharm Sci 2020;82(3):499-505 
directly affects the healing process. Due to the ability to accelerate wound healing, snail slime was assumed to have antiinflammatory activity. However, there is no scientific evidence for the antiinflammatory activity of snail slime. Therefore, the aim of this study was to evaluate the antiinflammatory activity of slime from the giant African snail (Lissachatina fulica) using various in vitro and in vivo methods.

\section{MATERIALS AND METHODS}

\section{Snail collection, identification, Slime collection and extraction:}

Thirty African snails (adult stage) were collected from Chiang Mai, Thailand. These land snails were morphologically identified according to Bouchet et al. ${ }^{[12]}$. Snails were stimulated to secrete slime by putting them on a plate, which was immersed in warm water $\left(32^{\circ}\right)$. The snails were scrubbed and then the slime was squeezed out from the snail body. The slime was collected and extracted with distilled water and ethanol. The slime was mixed with each solvent and stirred for $1 \mathrm{~h}$ and then centrifuged at $3500 \mathrm{rpm}$ for $10 \mathrm{~min}$. Supernatants of the slime were collected, lyophilized as aqueous and ethanol extracts (yield 7.0 and $1.4 \mathrm{mg}$ extract/ml slime, respectively). Evaluation of in vitro antiinflammatory activity,
antiproteinase activity:

This test was done according to a modified method of Oyedepo et al. ${ }^{[13]}$ and Sakat et al. ${ }^{[14]}$. Two millilitres reaction mixture $(0.06 \mathrm{mg}$ trypsin, $1 \mathrm{ml}$ of $20 \mathrm{mM} \mathrm{pH}$ 7.4 Tris HClbuffer and $1 \mathrm{ml}$ of the sample) was incubated at $37^{\circ}$ for $5 \mathrm{~min}$, then $1 \mathrm{ml}$ of $0.8 \%$ casein was added and incubated again for $20 \mathrm{~min}, 2 \mathrm{ml}$ of $70 \%$ perchloric acid was added and then the cloudy suspension was centrifuged. The absorbance of the supernatant was measured at $210 \mathrm{~nm}$, and sodium salicylate was used as a reference standard. The obtained absorbance was converted to percent antiproteinase activity using the Eqn. $1, \%$ inhibition $=[($ Abs control-Abs test $) /(\mathrm{Abs}$ control)] $\times 100$.

\section{Antilipoxygenase activity:}

Antilipoxygenase activity of extracts was evaluated using the method described by Shinde et al. ${ }^{[15]}$. The sample was prepared by dissolving the extract in $2 \mathrm{M}$ borate buffer ( $\mathrm{pH} 9.0$ ), $0.25 \mathrm{ml}$ of prepared sample was mixed with $0.25 \mathrm{ml}$ of lipoxidase $(20000 \mathrm{u} / \mathrm{ml})$ and incubated at $25^{\circ}$ for $5 \mathrm{~min}$. After that, $1.0 \mathrm{ml}$ of $0.6 \mathrm{mM}$ linoleic acid was added, mixed well and absorbance was measured at $234 \mathrm{~nm}$ and \% antilipoxygenase activity was calculated using Eqn. 1. In this test, indomethacin was used as a reference standard.

\section{Inhibition of protein denaturation:}

This assay was conducted according to the method of Kumari et al. ${ }^{[16]}$. The reaction mixture contained $0.2 \mathrm{ml}$ of egg albumin, $2.8 \mathrm{ml}$ PHS (pH 6.4) and $2 \mathrm{ml}$ of extract was incubated at $37^{\circ}$ for $15 \mathrm{~min}$ and heated at $70^{\circ}$ for $5 \mathrm{~min}$. After cooling to room temperature, absorbance of a sample was measured at $660 \mathrm{~nm}$ on a spectrophotometer. Percent inhibition of protein denaturation was calculated using Eqn, 1. Sodium salicylate was used as a reference standard.

\section{Membrane stabilization:}

Antihaemolytic activity was determined to find out the ability of the extracts to stabilize membranes. The procedure used was as described by Shinde et al. ${ }^{[15]}$. In this assay, red blood cells (RBC) suspension was prepared from the blood collected from rats (without NSAIDs), washed 3 times by centrifugation at $3000 \mathrm{rpm}$ for $30 \mathrm{~min}$ with normal saline. The pellet was resuspended to make a $10 \% \mathrm{RBC}$ suspension for the experiment. In the antihaemolytic test, $1 \mathrm{ml}$ of $10 \%$ $\mathrm{RBC}$ suspension was mixed with $1 \mathrm{ml}$ of the sample, heated at $56^{\circ}$ for $30 \mathrm{~min}$, cooled down under running tap water and centrifuged at $2500 \mathrm{rpm}$ for $10 \mathrm{~min}$. The absorbance of the supernatant was measured at $560 \mathrm{~nm}$. Percent antihaemolysis activity was calculated from Eqn. 1. In this study, indomethacin was used as a reference drug.

\section{In vivo antiinflammatory study:}

Male Wistar rats (Rattus norvegicus) were purchased from the National Laboratory Animal Center, Salaya, Nakhon Pathom, Thailand. The rats were housed in a controlled room, $25 \pm 1^{\circ}$ under $12 \mathrm{~h}$ light/dark cycle, with free access to water and food, for $7 \mathrm{~d}$ to acclimate. The experimental protocol used in this study was reviewed and approved by the Institutional Animal Care and Use Committee of the Biology Department, Faculty of Science, Chiang Mai University, Thailand (ID: Re 009/17).

\section{Ethyl phenyl propiolate (EPP)-induced ear edema assay:}

The procedure used in this assay was modified from the method of Kale et al..$^{[17]}$. Male Wistar rats, weighing 
35-40 g, were used in this study. Before treating, their ear thickness was measured with automatic Vernier calipers. Then, 2 doses of aqueous extract of snail slime (1 mg/ear and $2 \mathrm{mg} /$ ear) and phenylbutazone ( $1 \mathrm{mg} /$ ear), dissolved in $20 \mu \mathrm{l}$ of $50 \%$ ethanol (vehicle) were applied on both inner and outer left ears. Also, the vehicle was topically applied to the right ears (the negative control) in the same manner. Ear edema was then immediately induced by topical application of $5 \%$ EPP and ear thickness was measured after induction at 15, 30, 60 and $120 \mathrm{~min}$. Percent inhibition of edema $(\% \mathrm{EDI})=(\mathrm{EDC}-\mathrm{EDT}) / \mathrm{EDC} \times 100$, where, $\mathrm{EDC}$ is the oedema of control group obtained from ear thickness at X min-ear thickness at $0 \mathrm{~min}$, EDT is the oedema of test, ear thickness at $\mathrm{X}$ min-ear thickness at $0 \mathrm{~min}$.

\section{Cotton pellet-induced granuloma model:}

The method used in the study was the method reported by Agrawal et al. ${ }^{[18]}$ with a slight modification. Twenty male Wistar rats, weighing 180-200 g, were randomly divided into 4 groups (5 rats per group). The rats were anesthetized with intramuscular injections of thiopental. Four sterilized cotton pellets $(50 \pm 1 \mathrm{mg})$ were subcutaneously implanted on the back of the anesthetized rats (axillae and groin regions) with an aseptic technique. Two hours after the implantation, those rats were treated topically with aqueous extract of snail slime, $50 \%$ ethanol (vehicle) and diclofenac (standard). The treatment was given once a day for $7 \mathrm{~d}$. On day 8 , the pellets were dissected and weighed (wet weight), then they were dried at $60^{\circ}$ for $24 \mathrm{~h}$ and weighed again (dry weight). Percent inhibition of transudate and granuloma formations were calculated from wet and dry weights, respectively. Furthermore, the granuloma tissue was processed into histological slides stained with H\&E and Masson's trichrome to observe leukocyte infiltration and fibrosis. The tissue was also examined for oxidative stress through measurement of malondialdehyde (MDA) level and superoxide dismutase (SOD) activity, which represent lipid peroxidation and antioxidant enzyme, respectively.

\section{Evaluation of oxidative stress of granuloma tissue:}

The granuloma tissue $(20 \mathrm{mg})$ was homogenized in $1 \mathrm{ml}$ of $0.1 \mathrm{M}$ Tris- $\mathrm{HCl}$ buffer $\mathrm{pH} 7.4$ and centrifuged at $3000 \mathrm{rpm}$ for $10 \mathrm{~min}$ at $4^{\circ}$. The supernatant was collected for MDA and SOD measurement.

\section{MDA level measurement:}

The procedures followed the method of Uchiyama and Mihara ${ }^{[19]}$. About $100 \mu \mathrm{l}$ of the sample (collected supernatant) was pipetted into a screw cap tube, then $450 \mu 1$ of normal saline, $100 \mu 1$ thiobarbituric acid and $1000 \mu \mathrm{l}$ of $10 \%$ trichloroacetic acid we collected and mixed them well. The mixture was incubated at $100^{\circ}$ for $30 \mathrm{~min}$ and then cooled down under running tap water. Distilled water was added into the incubated solution, mixed well, and the mixture was centrifuged at $3000 \mathrm{rpm}$ for $10 \mathrm{~min}$. The supernatant was measured for absorbance at $532 \mathrm{~nm}$. The obtained absorbance was compared with the standard curve of tetramethoxypropane, and the MDA level was calculated from the standard curve and represented it as $\mathrm{nmol} / \mathrm{mg}$ protein.

\section{Measurement of SOD activity:}

The SOD activity was examined with a method modified from Takada et al. ${ }^{[20]}$. About $100 \mu \mathrm{l}$ of the sample (collected supernatant) was combined with $1 \mathrm{ml}$ reaction solution $(0.1 \mathrm{mM} \mathrm{Na}$-EDTA, $0.025 \mathrm{mM}$ nitroblue tetrazolium, and $3 \mathrm{mM}$ xanthine and $60 \mathrm{mM}$ sodium carbonate buffer). Then $100 \mu \mathrm{l}$ of xanthine oxidase was added and mixed well. The absorbance was measured at $560 \mathrm{~nm}$ every minute for $5 \mathrm{~min}$. The SOD activity was calculated from the absorbance and standard curve, and represented as unit/mg protein.

\section{Statistical analysis:}

Statistical analysis was performed using Statistical Package for the Social Sciences version 17. P value $<0.05$ was considered statistically significant.

\section{RESULTS AND DISCUSSION}

The slime extract showed antiproteinase activity, and the aqueous extract had a significantly higher effect than the ethanol extract. The aqueous extracts $(1000 \mu \mathrm{g} / \mathrm{ml})$ could inhibit proteinase activity up to $70.81 \pm 0.40 \%$, while the ethanol extract, at the same concentration, could inhibit only $43.27 \pm 0.23 \%$. Sodium salicylate (standard) was quite effective and caused 72.65 $\pm 0.44 \%$ inhibition at $70 \mu \mathrm{g} / \mathrm{ml}$ concentration.

In this study, it was found that the snail slime extracts had antilipoxygenase activity. The aqueous and ethanol extracts $(1000 \mu \mathrm{g} / \mathrm{ml})$ exhibited $37.19 \pm 3.15$ and $33.88 \pm 2.77 \%$ inhibition, respectively, which was not significant, while indomethacin inhibited up to $68.60 \pm 0.96 \%$ at $70.93 \mu \mathrm{g} / \mathrm{ml}$ concentration.

The protein denaturation inhibitory activity of snail slime extracts was detected in both aqueous and ethanol extracts. Both extracts displayed inhibitory activities, though the aqueous extract exhibited significantly 
better performance than the ethanol extract $(41.99 \pm 2.37$ and $12.76 \pm 3.61 \%$ at the concentration of $1000 \mu \mathrm{g} / \mathrm{ml})$. Indomethacin also inhibited denaturation; it could produce $41.82 \pm 13.85 \%$ inhibition at the concentration of $1000 \mu \mathrm{g} / \mathrm{ml}$ concentration.

Both snail slime extracts had a slight effect on membrane stabilization. The aqueous and ethanol extracts could reduce haemolysis of red blood cells, this was reflected in the percentage of inhibitions $(7.01 \pm 0.54$ and $13.42 \pm 0.28 \%$, respectively, at the concentration of $1000 \mu \mathrm{g} / \mathrm{ml}$ ). Indomethacin displayed highly effective antihemolytic activity; $100 \mu \mathrm{g} / \mathrm{ml}$ of indomethacin generated $23.15 \pm 4.13 \%$ of inhibition.

From in vitro study, it was found that the aqueous extract showed better activity than the ethanol extract. The aqueous extract was therefore selected to study further in in vivo models of acute and chronic inflammation. Snail slime extract reduced EPP-induced ear oedema at all time points studied as shown in Table 1 . The slime extract $(2 \mathrm{mg} / \mathrm{ear})$ at 60 and $120 \mathrm{~min}$ after oedema induction and phenylbutazone ( $1 \mathrm{mg} / \mathrm{ear})$ at 30,60 and $120 \mathrm{~min}$ after oedema induction showed significant inhibition relative to vehicle-treated ears. The slime extract at a dose of $1 \mathrm{mg} /$ ear could also reduce ear oedema, but this was not significant compared with the vehicle-treated ears.

The slime extract could significantly decrease both transudate and granuloma weights when compared to negative control group ( $<<0.05$, Table 2$)$. Diclofenac also significantly decreased the transudate and granuloma weights and compared to negative control group.
$\mathrm{H}$ and $\mathrm{E}$ staining showed dense leukocyte infiltration and fibroblast and collagen formation in the granuloma tissue of untreated rats (fig. 1). These features normally occur during inflammation. Granuloma tissues treated with diclofenac showed only a few scattered leukocytes and fibroblasts. Treatment with the slime extract showed decreased leukocyte infiltration compared with untreated rats, and showed fibroblast cells and collagen deposition. From Masson's trichrome stain, there was plenty of collagen formulated in the granuloma tissue of untreated rats as shown in fig. 2a. Treatment of slime extracts and diclofenac could reduce collagen deposition in granuloma tissue, as shown in fig. $2 b-d$.

From MDA measurement of granuloma tissue, it was found that the MDA level of granuloma tissue from rats treated with vehicle, diclofenac, $2.5 \%$ and $6.25 \%$ slime extract were, $1.13 \pm 0.052,0.88 \pm 0.053,0.96 \pm 0.010$ and $0.92 \pm 0.175 \mathrm{nmol} / \mathrm{mg}$ protein, respectively. These results showed that the extracts significantly reduced MDA levels compared to the negative control group $(p<0.05$; fig. 3a). SOD measurement indicated that the SOD activity of granuloma tissue from rats treated with vehicle, diclofenac, $2.5 \%$ and $6.25 \%$ slime extract were $20.37 \pm 10.25, \quad 52.48 \pm 12.57, \quad 44.90 \pm 7.35$ and $61.11 \pm 7.91 \mathrm{unit} / \mathrm{mg}$ protein $/ \mathrm{min}$, respectively. These results showed that the slime extract and diclofenac significantly increased SOD activity when compared to untreated rats (fig. 3b).

The inflammatory process involves a complex series of events, for instance the release of mediators and enzymes; leukocyte migration; and extravascular fluid accumulation $^{[21]}$. The results of this study indicated that snail slime extracts could ameliorate these inflammatory

TABLE 1: EFFECT OF SLIME EXTRACTS ON EPP-INDUCED EAR EDEMA IN RAT

\begin{tabular}{lccccccccc}
\hline \multirow{2}{*}{ Treatment } & \multicolumn{7}{c}{ Ear oedema thickness $(\mu \mathrm{\mu m})$} \\
\cline { 2 - 8 } & $\mathbf{0}$ min & $\mathbf{1 5}$ min & EDI (\%) & $\mathbf{3 0}$ & EDI (\%) & $\mathbf{6 0}$ & EDI (\%) & 120 & EDI (\%) \\
\hline Neg (right) & $394 \pm 10$ & $446 \pm 26$ & - & $466 \pm 10$ & - & $435 \pm 17$ & - & $437 \pm 20$ & - \\
PHE (left) & $397 \pm 30$ & $422 \pm 14$ & 51.92 & $423 \pm 24^{*}$ & 60.57 & $399 \pm 10^{*}$ & 94.62 & $406 \pm 10^{*}$ & 74.56 \\
Neg (right) & $405 \pm 13$ & $444 \pm 25$ & - & $452 \pm 23$ & - & $433 \pm 11$ & - & $427 \pm 19$ & - \\
E1 (left) & $392 \pm 20$ & $426 \pm 10$ & 12.82 & $429 \pm 14$ & 21.27 & $413 \pm 15$ & 25.00 & $411 \pm 10$ & 13.64 \\
Neg (right) & $406 \pm 20$ & $436 \pm 13$ & - & $449 \pm 20$ & - & $455 \pm 22$ & - & $450 \pm 19$ & - \\
E2 (left) & $397 \pm 16$ & $418 \pm 25$ & 15.45 & $422 \pm 19$ & 42.79 & $411 \pm 10^{*}$ & 71.14 & $410 \pm 10^{*}$ & 70.10 \\
\hline
\end{tabular}

${ }^{*}$ Means significant difference with negative control $(p<0.05)$. Neg is negative control, PHE is phenylbutazone; E1 is extract $1 \mathrm{mg} /$ ear; E2 is extract $2 \mathrm{mg} /$ ear; EDI is edema inhibition

TABLE 2: EFFECT OF SLIME EXTRACTS ON COTTON PELLET-INDUCED GRANULOMA IN RATS

\begin{tabular}{lcccc}
\hline & Transudate weight $(\mathrm{mg})$ & \% Inhibition of transudate & Granuloma weight $(\mathrm{mg})$ & \% Inhibition of granuloma \\
\hline Neg & $577.12 \pm 46.86$ & - & $99.94 \pm 12.87$ & - \\
Diclofenac & $297.96 \pm 21.65^{*}$ & 48.37 & $47.13 \pm 5.76^{*}$ & 52.84 \\
E2.5 & $433.17 \pm 25.76^{*}$ & 24.94 & $78.28 \pm 5.23^{*}$ & 21.68 \\
E6.25 & $411.74 \pm 21.49^{*}$ & 28.64 & $73.68 \pm 6.74^{*}$ & 26.28 \\
\hline
\end{tabular}

*Mean significant difference $(\mathrm{p}<0.05)$. Neg is negative control treated with vehicle, E2.5 is $2.5 \%$ extract and E6.25 is $6.25 \%$ extract 


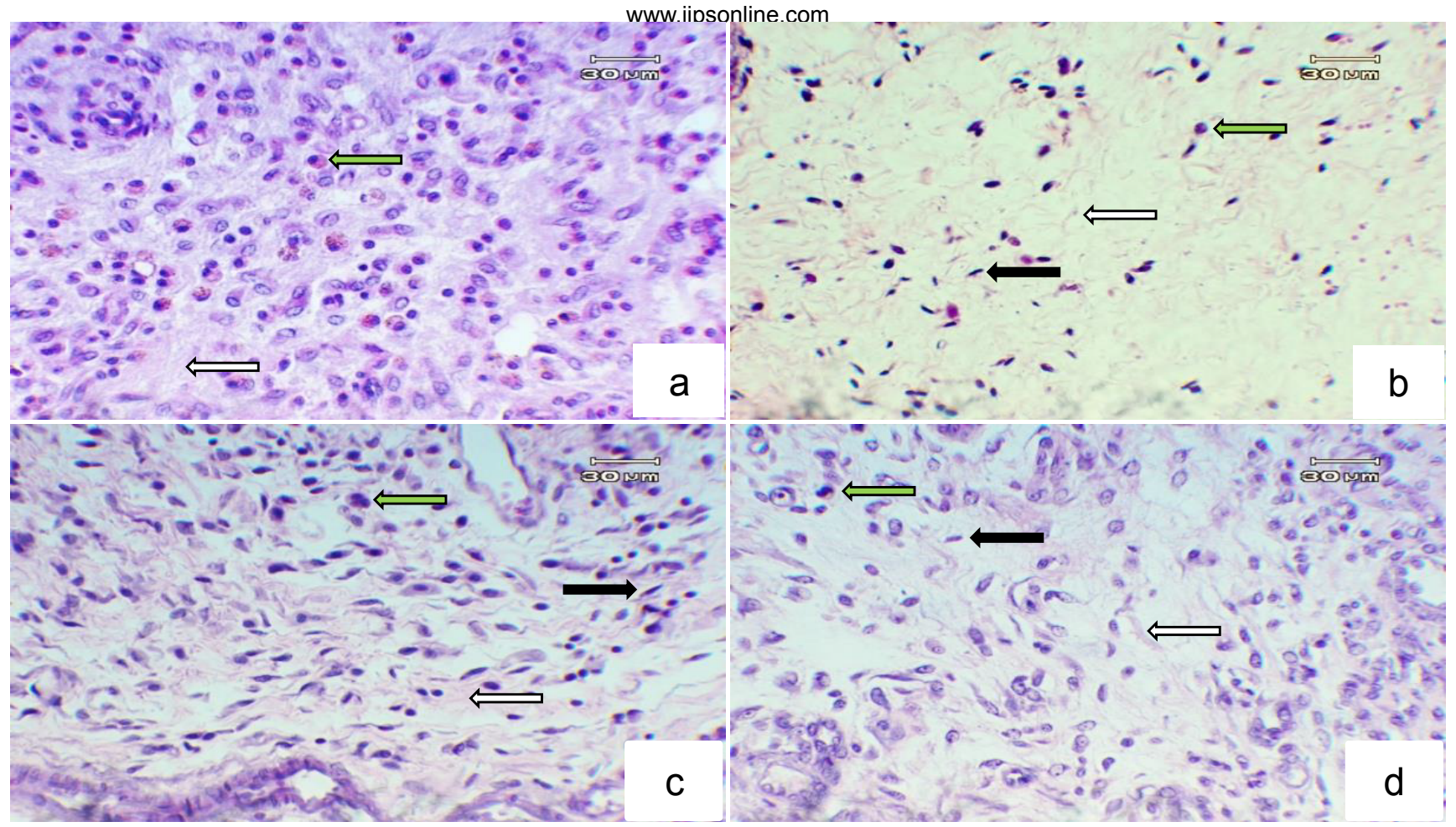

Fig. 1: Histopathology section of granuloma tissue (H\&E stain 20X)

$(\Longleftrightarrow)=$ inflammatory cells; $(\Longleftrightarrow)=$ collagen fiber; $(\longleftarrow)=$ fibroblast cell. (a) Negative control group, (b) diclofenac, (c) slime extract $(2.5 \%)$ and (d) slime extract (6.25\%). (a) The section in negative control group displayed severe inflammation with dense leukocytes and collagen formation. (b) The section of granuloma tissue in diclofenac-treated group showed mild inflammation with few leukocytes and fibroblasts. (c and d) The granuloma section in groups treated with slime extract both doses showing moderate inflammation with decreasing inflammatory cells
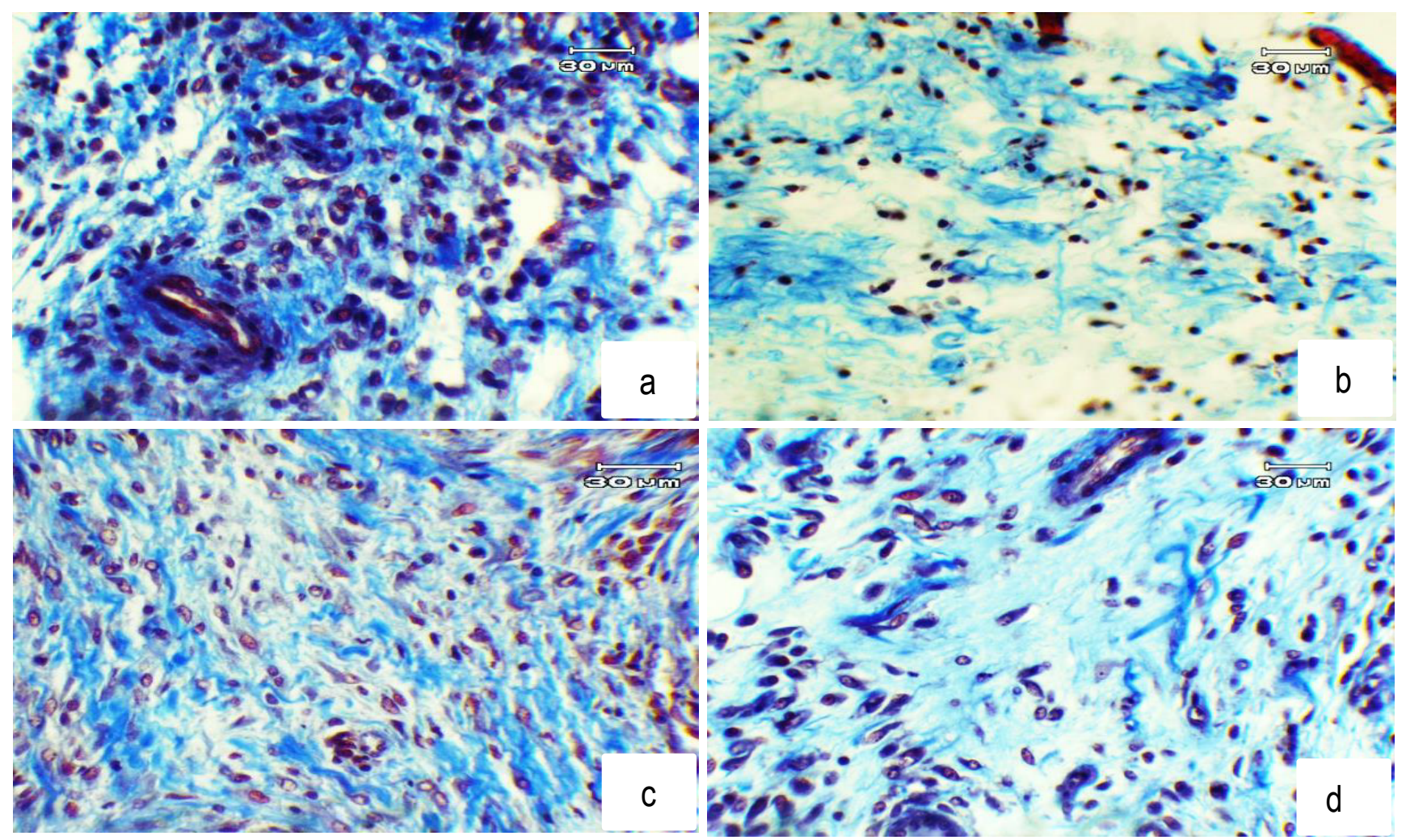

Fig. 2: Histopathology section of granuloma tissue (Masson's trichrome stain 20X)

(a) Negative control group, (b) diclofenac, (c) slime extract $(2.5 \%)$ and (d) slime extract (6.25\%). (a) The section in the negative control group revealed thick collagen deposition (indicated in blue) during granuloma formation. (b) The section for the diclofenactreated group showed light collagen deposition during granuloma formation. (c and d) The granuloma section in groups treated with slime extracts, both doses, showed collagen synthesis in the 2 groups were lower than that of the negative control 


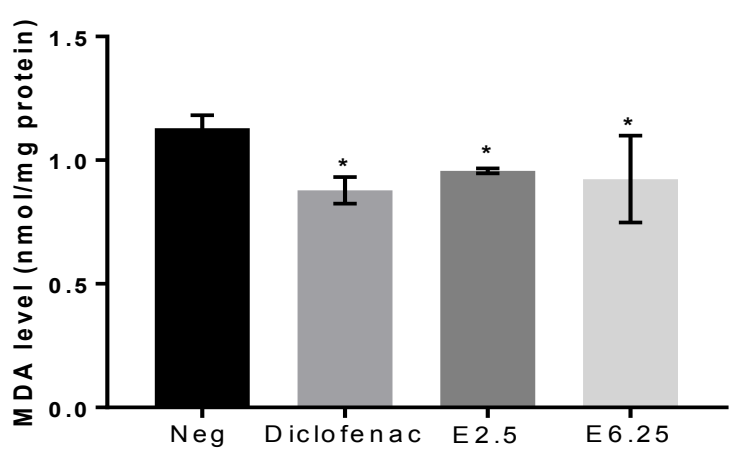

A

Groups

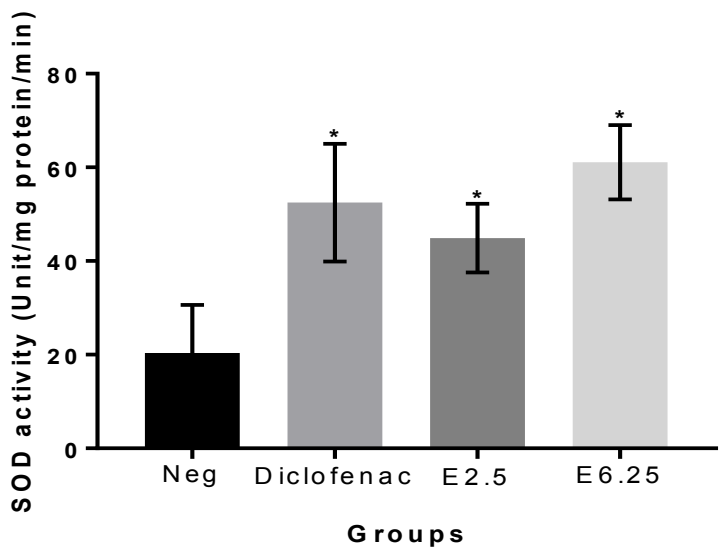

Fig. 3: Effect of treatments MDA levels and SOD activity of granuloma tissue

Each column represent mean \pm SD $(n=5)$, *represents significant difference $(p<0.05)$ when compared with negative control

events due to thier antiinflammatory activity. From in vitro study, the slime extracts showed mechanisms of action through different pathways, including inhibitions of inflammatory enzymes, membrane stabilization and antiprotein denaturation. Diclofenac used as standard references in in vitro, also displayed antiinflammatory activity in every assay.

An EPP-induced ear edema test was used to verify antiinflammatory activity against acute inflammation in the aqueous extract, in vivo. Topical application of EPP causes release of the inflammatory mediators, histamine, serotonin, bradykinin and prostaglandins. These mediators promote vascular permeability, vasodilation and accumulation of fluid in tissues, which lead to ear edema $^{[22,23]}$. In this study, high dose of slime extract could significantly reduce ear thickness indicating that the slime extract had antiinflammatory properties and the mechanism of action might be through inhibiting the mediators of the acute phase of inflammation. Phenylbutazone used in the experiment, also inhibited the induced ear oedema and showed higher efficacy than both doses of the extract. Phenylbutazone is an inhibitor of cyclooxygenase, which decreased amplification of the inflammatory signals, leading to decreased inflammation. Slime extract and phenylbutazone generated highest $\%$ inhibition at $60 \mathrm{~min}$, raising the possibility that the main mechanism of action of the slime extract is related to inhibition of cyclooxygenase.

Chronic inflammation occurs when the acute inflammatory response cannot eliminate the harmful stimuli. The chronic response is divided into two phases; the transudative/exudative phase and the proliferative phase. The transudative phase is the initial phase, characterized by increased vascular permeability and vascular protein leakage ${ }^{[24]}$. The proliferative is the later phase, in which granuloma tissue is formed that is characterized by leukocyte infiltration, fibroblast proliferation, collagen formation and angiogenesis ${ }^{[24,25]}$. In the cotton pellet-induced granuloma assay, the wet weight of the cotton pellet was used to determine transudate volume, and the dry weight of the cotton pellet was used to evaluate granuloma formation ${ }^{[26]}$. In present study, slime extract showed antiinflammatory activity in both phases. In the transudative phase, the result indicated an inhibitory effect of the slime extract on vascular permeability, vasodilation and accumulation of extravascular fluid. In the proliferative phase, the snail slime extract could inhibit granuloma formation, which was shown by reduction in granuloma weight. Histopathology of granuloma showed the decreasing of inflammatory cell and collagen deposition in the granuloma tissues of the slime extract treated groups. It was clear that the slime extract affected to the formation of granuloma tissue. This suggested the inhibitory activity of the extract on leukocyte migration and collagen formation at site of inflammation. This might have been due to the ability of the slime extract to decrease the inflammatory signals that enhance the granuloma formation. It was reported that extracts from snails could decrease plasma IL-6, an inflammatory cytokine in osteoarthritis-induced $\operatorname{dog}^{[27]}$ and decrease COX level induced in inflammatory keratinocytes ${ }^{[28]}$. In the study, the slime extracts also improved the oxidative status of cotton-pellet induced granuloma in rats. This effect might have been due to its antioxidant properties. The previous study found that this snail slime had SOD activity and had antilipidperoxidation activity ${ }^{[29]}$. Thus, it is possible that antioxidant activity might be another mechanism of action in the slime extract to improve inflammatory status.

The results of the present study demonstrated the in vitro and in vivo antiinflammatory activity of slime extracted from giant African snails (Lissachatina fulica). Thus it could be concluded that the snail slime extracts 
have antiinflammatory activity with potential to be developed as antiinflammatory products. Although this study revealed some mechanisms of action of the slime extracts, further study is necessary to probe it's activity in different models.

\section{Acknowledgements:}

Authors would like to thank the Science Achievement Scholarship of Thailand, the Department of Biology in the Faculty of Science at Chiang Mai University and the Graduate school, Chiang Mai University. This research work was partially supported by Chiang Mai University and Research Center in Bioresources for Agriculture, Industry and Medicine, Chiang Mai University.

\section{REFERENCES}

1. Ferrero $\mathrm{ML}$, Nielsen $\mathrm{OH}$, Andersen PS, Girardin SE. Chronic Inflammation: Importance of NOD2 and NALP3 in Interleukin-1 Beta Generation. J Clin Exp Immunol 2007;147:227-35.

2. Simon LS, Weaver AL, Graham DY, Kivitz AJ, Lipsky PE, Hubbard RC, et al. Anti-inflammatory and Upper Gastrointestinal Effects of Celecoxib in Rheumatoid Arthritis: A Randomized Controlled Trial. JAMA 1999;282:1921-8.

3. Singh N, Kumar RP, Kumar S, Sharma S, Mir R, Kaur P, et al. Simultaneous Inhibition of Anti-coagulation and Inflammation: Crystal Structure of Phospholipase A2 Complexed with Indomethacin at $1.4 \AA$ Resolution Reveals the Presence of the New Common Ligand-binding Site. J Mol Recognit 2009;22:437-45.

4. Richter KO. Movement, Reproduction, Defense and Nutrition as Functions of the Caudal Mucus in Ariolimax columbianus. Veliger 1980;23:43-7.

5. Faculty of Pharmacy, Mahidol University. Snail slime and its pharmaceutical and cosmetic properties [cited 10 January, 2019]. Available from: https://www.pharmacy.mahidol.ac.th/ th/knowledge/ article/276.

6. Iguchi SMM, Aikawa T, Matsumoto JJ. Antibacterial Activity of Snail Mucus Mucin. Comp Biochem Physiol 1982;72:5714.

7. Etim LB, Aleruchi C, Obande GA. Antibacterial Properties of Snail Mucus on Bacteria Isolated from Patients with Wound Infection. Br Microbiol Res J 2016;11:1-9.

8. Brieva A, Philips N, Tejedor R, Guerrero A, Pivel JP, AlonsoLebrero JL, et al. Molecular Basis for the Regenerative Properties of a Secretion of the Mollusk Cryptomphalus aspersa. Skin Pharmacol Physiol 2008;21:15-22.

9. E-kobon $\mathrm{T}$, Thongararm P, Roytrakul S, Meesuk L, Chumnanpuenb, P. Prediction of Anticancer Peptides Against MCF-7 Breast Cancer Cells from the Peptidomes of Achatina fulica Mucus Fractions. Comput Struct Biotechnol J 2016;14:49-57.

10. Harti AS, Sulisetyawati SW, Murharyati A, Oktariani M, Wijayanti IK. The Effectiveness of Snail Slime and Chitosan in Wound Healing. Int J Pharma Bio Sci 2016;5:76-80.

11. Atik $\mathrm{N}$ and Iwan ARJ. The different effect of topical Aloe vera with abruption povidone iodine on incision wpund healing skin of mice (Mus musculus). Majalah Kedokteran Bandung 2009;41:29-36.
12. Bouchet P, Rocroi JP. Classification and Nomenclator of Gastropod Families. Malacologia 2005;47:1-368.

13. Oyedepo OO, Femurewa AJ. Antiprotease and Membrane Stabilizing Activities of Extracts of Fagara Zanthoxyloides, Olax Subscorpioides and Tetrapleura Tetraptera. Int J Pharmacogn 1995;33:65-9.

14. Sakat $\mathrm{S}$, Juvekar $\mathrm{AR}$, Gambhire MN. In vitro Antioxidant and Anti-inflammatory Activity of Methanol Extract of Oxalis corniculata Linn. Int J Pharm Pharm Sci 2010;2:146-55.

15. Shinde UA, Phadke AS, Nari AM, Mungantiwar AA, Dikshit VJ, Saraf MN. Membrane stabilization activity- a possible mechanism of action for the anti-inflammatory activity of Cedrus deodara wood oil. Fitoterapia 1999;70:251-7.

16. Kumari S, Yasmin $\mathrm{N}$, Hussain $\mathrm{MR}$, Babuselvam $\mathrm{M}$. In vitro anti-inflammatory and anti-arthritic property of Rhizopora mucronata leaves. Int J Pharm Sci Res 2015;6:482-5.

17. Kale M, Misar AV, Dave V, Joshi M, Mujumdar AM. Antiinflammatory Activity of Dalbergia lanceolaria Bark Ethanol Extract in Mice and Rats. J Ethnopharmacol 2007;112:300-4.

18. Agrawal R, Sandhu SK, Sharma I, Kaur IP. Development and Evaluation of Curcumin-loaded Elastic Vesicles as an Effective Topical Anti-inflammatory Formulation. AAPS PharmSciTech 2014;16:364-74.

19. Uchiyama M, Mihara M. Determination of Malonaldehyde Precursor in Tissues by Thiobarbituric Acid Test. Anal Biochem 1978;86:271-8.

20. Takada Y, Noguchi T, Kayiyama M. Superoxide Dismutase in Various Tissues from Rabbits Bearing the Vx-2 Carcinoma in the Maxillary Sinus. Cancer Res 1982;42;4233-5.

21. Vane JR, Botting RM. Anti-inflammatory Drugs and Their Mechanism of Action. Inflamm Res 1998;47:78-87.

22. Brattsand R, Thalen A, Roempke K, Kallstrom L, Gruvstad E. Influence of 16 Alpha, 17 Alphaacetal Substitution and Steriod Nucleus Fluorination on the Topical to Systemic Activity Ratio of Glucocorticoids. J Steroid Biochem 1982;16:779-86.

23. Carlson RP, O'Neil-Davis L, Chang J, Lewis AJ. Modulation of Mouse Ear Edema by Cyclooxygenase and Lipoxygenase Inhibitors and Other Pharmacologic Agents. Agents Actions 1985; 17:197-204.

24. Babu NP, Pandikumar P, Ignacimuthu S. Anti-inflammatory activity of Albizia lebbeck Benth., an ethnomedicinal plant, in acute and chronic animal models of inflammation. J Ethnopharmacol 2009;125:356-60.

25. Pingsusaen $\mathrm{P}$, Kunanusorn $\mathrm{P}$, Khonsung $\mathrm{P}$, Chiranthanut $\mathrm{N}$, Panthong A, Rujjanawate C. Investigation of Antiinflammatory, Antinociceptive and Antipyretic Activities of Stahlianthus Involucratus Rhizome Ethanol Extract. J Ethnopharmacol 2015;162:199-206.

26. Damre AA, Damre AS, Saraf MN. Evaluation of Sesquiterpene Lactone Fraction of Saussurea lappa on Transudative, Exudative and Proliferative Phases of Inflammation. Phytother Res 2003;17:722-5.

27. Ajadi AR, Gazal OS, Otesile EB, Kasal OB. Evaluation of glucosamine and snail mucin on the progression of experimental knee osteoarthritis in dogs. Int J Morphol 2013; 31:280-6.

28. Kuanpradit C, Jaisin Y, Jungudomjaroen S, Mitu SA, Puttikamonkul S, et al. Attenuation of UV-B exposure-induced inflammation by abalone hypobranchial gland and gill extracts. Int J Mol Med 2017;39:1083-90.

29. Wiya C, Saenphet S, Saenphet K. Antioxidant Activity of Slime Extract from Giant African Snail (Lissachatina fulica). International Conference of Agriculture and Natural Resources 2018. pp. 118-121. 